\title{
Correction: MicroRNA-221 inhibits autophagy and promotes heart failure by modulating the $\mathrm{p} 27 / \mathrm{CDK} 2 / \mathrm{mTOR}$ axis
}

\author{
M Su · J Wang $\cdot$ C Wang $\cdot$ X Wang $\cdot$ W Dong $\cdot$ W Qiu $\cdot$ Y Wang $\cdot$ X Zhao $\cdot$ Y Zou $\cdot$ L Song $\cdot L$ Zhang $\cdot$ R Hui \\ Published online: 6 July 2020 \\ (c) The Author(s), under exclusive licence to ADMC Associazione Differenziamento e Morte Cellulare 2020
}

\section{Correction to: Cell Death \& Differentiation https://doi.org/10.1038/cdd.2014.187 published online 30 September 2019}

Since online publication of this article, the authors noticed that there were errors in the images used to compile
Fig. 3c, 3g, and Supplementary Fig. 3g. The corrected images are provided below.

The authors confirm that these errors do not affect the conclusions of the study, and apologise for any inconvenience caused. 

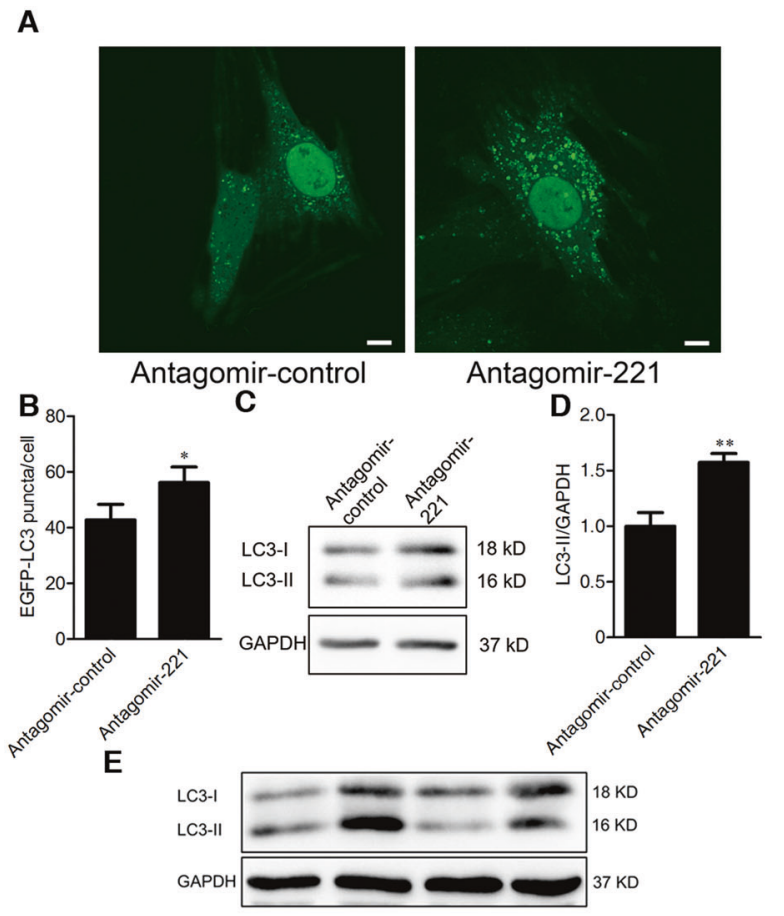

F

Scramble + $\operatorname{miR}-221$
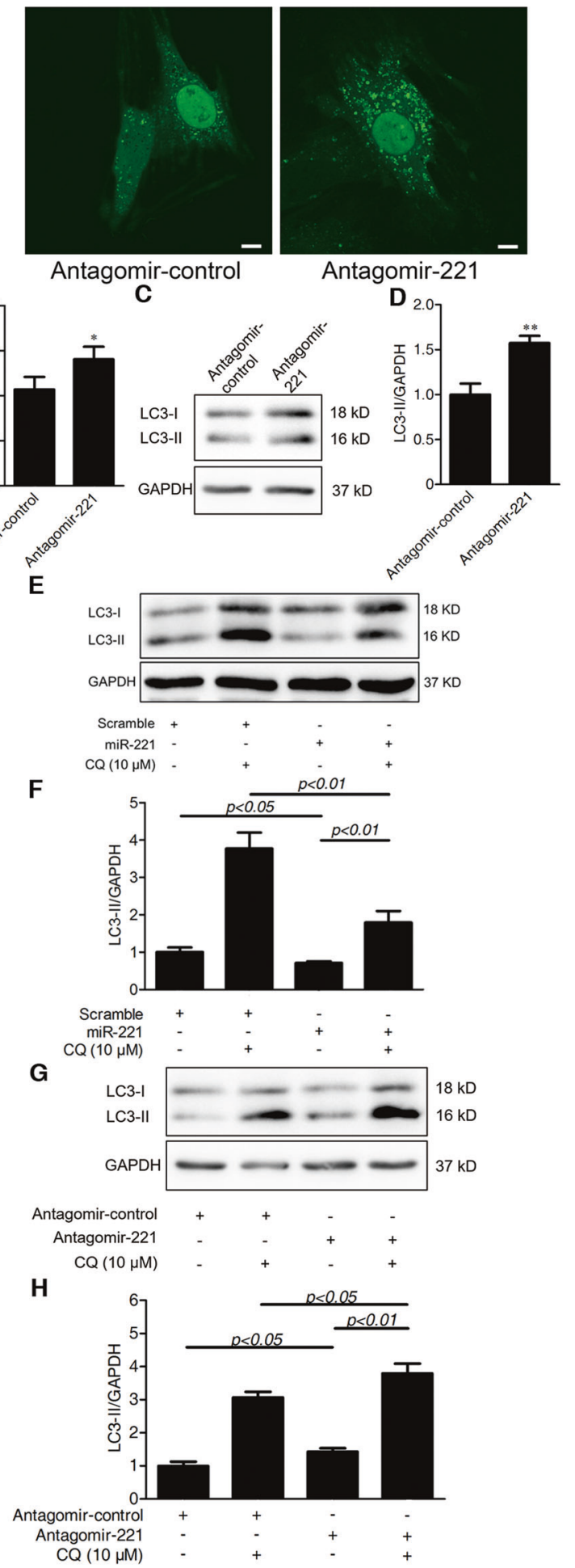

omir-221
|

Antagomir-contro

Antagomir-22

Bafilomycin A1
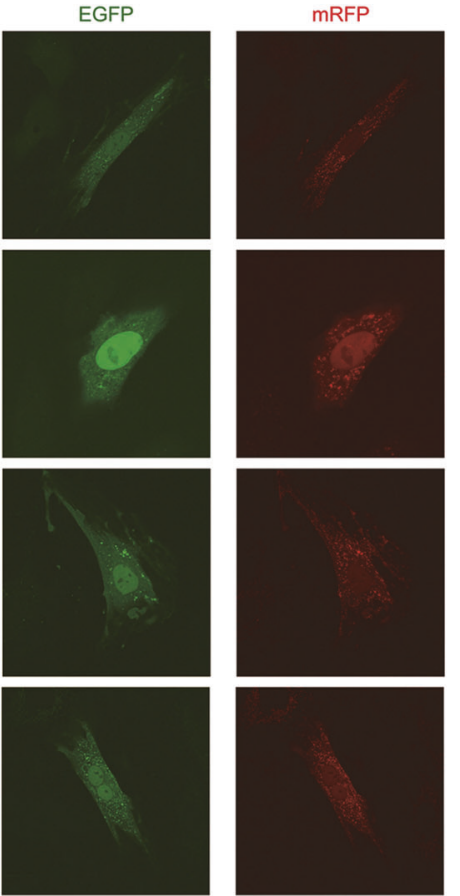

Rapamycin
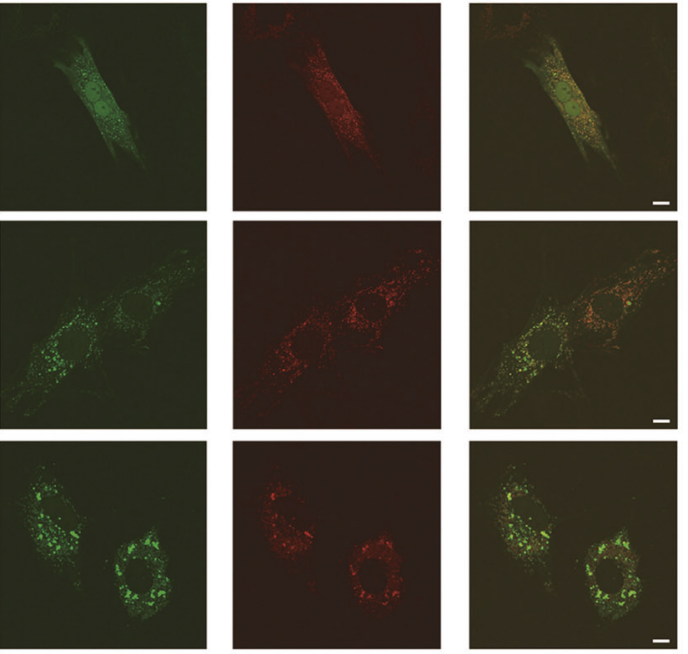

J

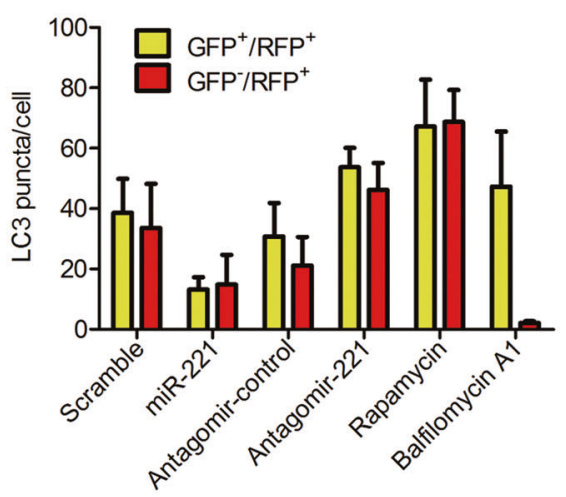

Fig. 3 


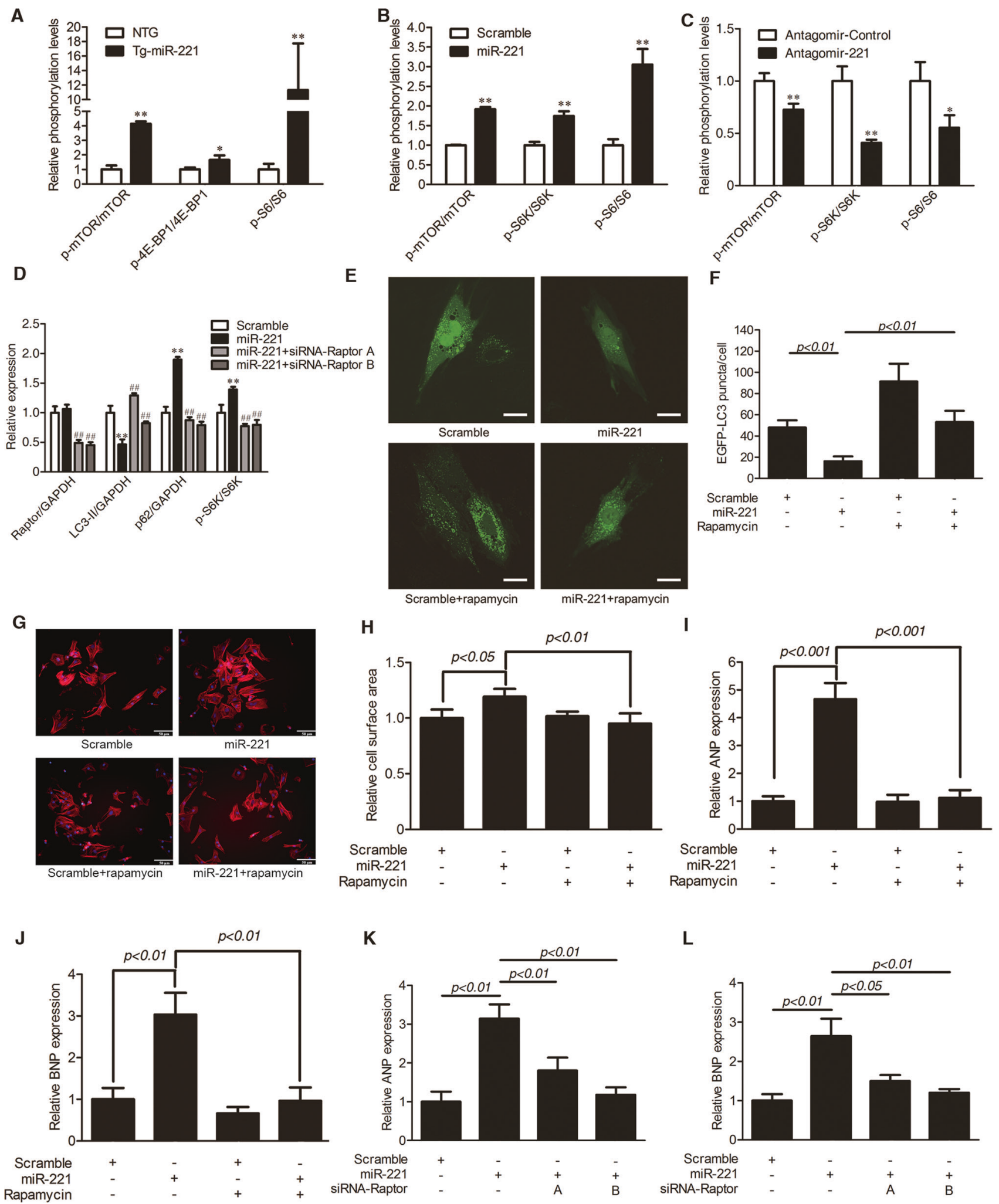

Supplementary Fig. 3 